Review Article

\title{
A Comparative Study of the Impact of the Stirrer Design in the Stir Casting Route to Produce Metal Matrix Composites
}

\author{
Farooq Muhammad $(1)$ and Shawnam Jalal $(D)$ \\ Department of Mechanical \& Mechatronics Engineering, College of Engineering, Salahaddin University, Erbil, Iraq \\ Correspondence should be addressed to Farooq Muhammad; farooq.muhammad@su.edu.krd
}

Received 28 July 2021; Accepted 3 September 2021; Published 23 September 2021

Academic Editor: Necmettin Maraşlı

Copyright (c 2021 Farooq Muhammad and Shawnam Jalal. This is an open access article distributed under the Creative Commons Attribution License, which permits unrestricted use, distribution, and reproduction in any medium, provided the original work is properly cited.

\begin{abstract}
Aluminum matrix composites are widely utilized in many sectors, and their popularity is rising due to their ability to combine high mechanical characteristics with their lightweight. Stir casting is typically achieved in a closed crucible with an invisible flow pattern to produce aluminum alloy matrix composites. Researchers employed a hybrid method to optimize the stir casting parameters. The vast number of parameters and their overlap affects the uniform distribution of reinforcement particles. Investigators on their way to the best technique have gotten promising outcomes in their specific situations, but they still need more work to be able to generalize their findings to optimize the stirrer design to get efficient mixing. Due to an experimental technique alone is insufficient for optimizing stir casting parameters, researchers combined theoretical, experimental, statistical, and numerical simulation approaches to get more precise and reliable findings. The design of the experiment (DOE), particularly Taguchi, and other standard statistics such as ANOVA and regression were discovered to be the most often utilized statistical contributions. Recent attempts to simulate stir casting have begun to match the experimental or analog model data by developed numerical software and analytical analysis. Finally, previous study results and suggestions were collected and compared, arranged, revised, and presented simply about the proper stirrer design, stages, and position in that to make the paper unique.
\end{abstract}

\section{Introduction}

Market analysts expect significant growth in demand for composites, which will exceed 6\% between 2020 and 2027 [1]. Stir casting is an indispensable route to produce metal matrix composites [2-4]. It is one of the best methods for making AAMCs because of its simplicity, low cost of production, and mass production ability [5]. As it appears from the previous review articles, the experimental method alone is often unable to discover the optimal stir casting manufacturing of the metal matrix composites, so researchers mixed methods for better understanding and prediction. The theoretical, experimental, analytical, statistical, and numerical simulations in hybrid methodology have been all mixed to obtain more accurate and valid results. Several studies have looked at the impact of stirrer design on mixing time and power usage. They concluded that impeller design affects mixing time [6].
Stirrer design, stirring time, and stirring speed are the key variables that impact the stir casting method; when properly determined and adjusted they result in an improvement in the quality of the stir casting products [7]. The proper design of experiments was not used by many researchers, so there is no clarification and analysis of the interactions between the various inputs [8-10]. Authors investigated that the stirring casting process is not obvious enough, and the reason behind the particle distribution is not comprehended for the aluminum ceramic powder composite [11]. In addition, the researchers analyzed the complexity and difficulty of understanding the $\mathrm{SiC}$ particles distribution process in the aluminum alloy, including the interaction between particles themselves and with the matrix alloy [11]. Others criticized the lack of clarity about the effects of the blade angle, the impeller diameter, the stirrer geometry, and the interaction of these parameters on the flowing characteristics in the stirred crucible during stir 
casting [12]. The designer in the chemical industry managed to find the better design impellers for solid suspension, because less power is required, whereas lower energy means lower energy costs [13]. In stir casting, reducing stirring time is also a necessity for a more environmentally friendly manufacturing process through optimizing other stirring parameters especially the stirrer design and its position. An increase in stirring time in the AAMC stir casting manufacturing might lead to good dispersion of microceramics powder into the aluminum alloy matrix, but it is the energy consumption and cost. Yang et al. stated that, with the extension of the stirring time, the particle dispersion in the composite is more uniform when they investigated the effect of stirring parameters on the distribution of $\mathrm{SiC}$ particles in AMCs by using experimental and computational methods [11]. Over the past decades, much energy and attention have gone to optimize the mechanical properties of MMCs, but unfortunately, the flow pattern during stirring cannot be observed as they are done in closed furnaces, which are nontransparent; direct measurements also are dangerous, time-consuming, and not effective. To avoid these challenges statistical analysis and numerical simulation are used beside experiments [8, 14].

\section{Statistical Analysis}

The trial and error approach is used to discover the optimal parameters for creating a quality product while optimizing a manufacturing process. However, this method demands extensive experimental work and, it results in a great waste of time and money [15]. Until the 1920s, the researchers have used one-factor-at-a-time (OFAT) experiments. They vary only one factor (variable) at a time while keeping others factors (variables) fixed that can produce misleading results when reactions are present [16]. Box stated that Fisher made great contributions to the design of experiments when he conducted for the first time the design of experiments (DOEs) in his experimental agriculture research when he used a statistical approach like F- test mean [16]. The concept of experimentation using an orthogonal array dates back to Fisher [17]. In the 1950s, George Box was tasked with optimizing and reducing variation in the chemical manufacturing process when he invents the response surface method to change (DOE) purpose from explanation to prediction. One-factor-at-a-time (OFAT) method was applied by some researchers to choose the stirring parameters for studying one factor while the other variables were constant. The downside of using OFAT is that it is inefficient which results in an unnecessarily large number of experimental runs. To ensure the reliability of the data, the average value of the experiments was recorded several times for each condition, and several measurements were taken for each sample [18, 19]. The Taguchi method utilizes orthogonal arrays from the design of experiments theory to study a large number of variables with a small number of experiments. Using orthogonal arrays significantly reduces the number of experimental configurations to be studied [20]. The Taguchi technique was used to create the product and process design. For all conceivable process circumstances, the experiment design was utilized to explore factors and associated variables. The Taguchi experimental strategy was used to find control variables that reduce process changeability by reducing the impact of uncontrolled noise sources. The noise factors cannot be controlled during production processes, but they can be controlled during experimentation. The particle size, the weight $\%$ of reinforcing particles, and stirring time are the key influencing parameters. The variation of response was studied with the help of the $\mathrm{SN}$ ratio. The larger the better criterion was assumed for nine trials of strength hardness [21]. Several optimization methods are used to optimize the process parameters of the stir casting process. The most prominent ones are Taguchi techniques, grey relational analysis, regression analysis, multiobjective Taguchi method, genetic algorithm, analysis of variance (ANOVA), fuzzy logic [22], swarm optimizer [23], and finite element method. Vijian and Arunachalam used multivariable linear regression analysis to form a mathematical model. The weighted sum technique is used to choose the goal functions for the genetic algorithm based on the regression analysis. To improve the mechanical characteristics of the composites, a genetic algorithm is utilized as a tool [24]. Senthil and Amirthagadeswaran conducted experiments based on the Taguchi technique for parameter optimization in the squeeze casting process. The confirmation test showed improved mechanical properties in the produced composites [25]. Goyal et al. developed a mathematical model and predicted the optimum process parameters using regression analysis technique. The optimum levels of parameters produced improved mechanical properties, which was validated using ANOVA [26]. The authors used a statistical approach, Taguchi, ANOVA, response surface, and regression to optimize different stirring parameters to get optimal MMCs mechanical properties; however, a few papers looked into the factors related to stirrer design [2, 27-40].

\section{Numerical Analysis}

Since the 1950s, the practice of mixing has seen a rise in knowledge, experience, and dynamics which resulted in the publication of works by Uhl and Grey, Nagata, Harnby et al., and Baldyga and Bourne [10]. Bui et al. used the model to investigate the impact of tank geometry and stirrer activity on mixing. A two-phase flow, three-dimensional, steadystate is used to study the flow field and volume fraction distribution in a stirred tank [41]. Since the 1990s, rapid progress has been made in numerical simulation of the fluid flow problems using CFD, which is widely used in the chemical industry for a variety of operations such as catalytic reactions, leaching, polymerization, etc. [12]. Since the beginning of the third millennium in 2002 and 2003, the first attempts to simulate stir casting have started by Hashim and Naher, respectively. They prove the importance of using simulation model tools in the production of MMCs $[8,42]$. Several optimization methods are used to optimize the process parameters of the stir casting process when the most prominent one is a finite element method. Gore and Crowe stated that when the size of the reinforcement particles is 
tiny concerning the turbulent length scale, the reinforcement particles tend to follow the turbulent fluid motion. On the other hand, large particles tend to be accumulating in the shear zones instead of following the turbulent motions [43]. Kocaefe and Bui used a one-phase flow mode to test how one-phase modeling using the algebraic slip model approach can represent the sedimentation and the stirring process, as compared to the two-phase model. Indeed, the one-phase model has two significant benefits over the two-phase model: it takes less computer time and can allow for a particle size distribution to realistically characterize a class of particulate materials [44]. Rohatgi et al. used the model SiC-water system to investigate the effects of the polarity of the different blade angles on the power required for homogeneous mixing. They concluded the change in power, decreasing with an increase in blade angle from $20^{\circ}$ to $60^{\circ}$ [45].

\section{Reviews of Statistical and Numerical Contributions to the Stirrer Design}

Hashim et al. used finite element analysis and employed a specialized computational fluid dynamics package to simulate the fluid flow and thus dispersion of reinforcement material in a molten matrix alloy during stirring [46]. The simulation shows that the stirring parameters such as impeller position in the crucible have a significant effect on the flow behavior of the fluid. Despite some limitations arising from the simplification of the physical situation, a model is a useful tool in specifying process parameters in the production of MMCs. Hashim et al. applied software ANSYS Flotran-CFD in their simulation, the model being built using two-dimensional elements when the Newtonian flow of the aluminum was presumed for simulation. They used a stirrer that has as simple geometry as possible.

They used macroscopic or continuous flow to simplify the analysis. Glycerol and polystyrene particles were used in a Perspex crucible [46]. The simulation focuses on the fluid flow pattern for different positions of a stirrer in a crucible and different speeds of stirring for two fluids: molten aluminum and glycerol. The flow velocity and direction have been affected by the speed of rotation of the stirrer. At higher speeds an undesirable vortex forms on the fluid surface. They also confirmed the role of stirrer location when the impeller is placed excessively high within the fluid; little flow occurs at the base of the vessel where it is required to lift particles into the melt.

Hashim et al. stated that the optimum diameter of the stirrer is the size at which solid particles are fluidized in both the central and peripheral parts at the same speed. It has been confirmed that, for a flat-bottom vessel, stirrer diameter should be equal to $0.4 \mathrm{D}$, where $\mathrm{D}$ is the diameter of the vessel, and the blade width should be equal to $0.1-0.2 \mathrm{D}[46,47]$.

Hashmi et al. used streak photography of tracer particles in such a visualization experiment as a good method for indicating the overall flow pattern and existence of stagnant regions of fluid. However, it is noted that it is not suitable for showing the rate of mixing between different parts of a vessel. Finally, they stated that the particle dispersion number (PDN) should be greater than four for homogeneous dispersion [46]. Solid particles tend to stay undispersed in the center of the vessel bottom where the diameter is too large. When the stirrer diameter is too small, despite the lack of deposits in the middle, the solid particles remain suspended at the vessel's periphery [46].

As solid particles in a liquid are agitated in a cylindrical vessel, when the agitator speed is low, a deposit of solid particles forms on the bottom [47]. Hashim et al. stated that these two types of solid particle fluidization shown in Figure 1 are influenced by stirrer geometry [46].

Naher et al. used visualization simulation to understand the particle distribution in the glycerol/water system with the simulation that had been conducted with similar characteristics of liquid and particle. The simulation includes visualization experiments. Other fluids with similar properties are used to substitute liquid and semisolid aluminum in the visualization studies. Three types of stirrers were used to provide agitation: three- and four-bladed stirrers with blades parallel to the axis of rotation, as well as a fixed-bladed turbine stirrer. Figure 2 shows the dimensions of a flatbottomed cylindrical crucible with $80 \mathrm{~mm}$ diameter and $105 \mathrm{~mm}$ inner diameter. Figure 3 shows the four flat-blade impellers, with $10 \mathrm{~mm}$ width and $2 \mathrm{~mm}$ thickness, and in all tests height was $20 \mathrm{~mm}$ from the base of the crucible. The important conclusion related to stirrer design was that a blade angle has a significant effect on particle distribution in the water mixture and higher blade angles reduced particulate dispersion time [8].

Aubin and Xuereb used ANSYS CFX to study the effect of the design of multiple impellers on the mixing of highly viscous fluids' stirred tanks. The tank geometry is a flatbottom cylindrical tank. Figure 4 explains the dimensions. $T=1 \mathrm{~m}, H=2 \mathrm{~m}$, the diameter of four Intermig impellers is $(D)=0.9 \mathrm{~T}$, the off-bottom clearance with four Intermig impellers $=C 0$ where the lowest impeller is $0.22 \mathrm{~T}$, and distance separating impellers $=C 1=0.4 \mathrm{~T}$ for the two lowest Intermigs and $0.45 \mathrm{~T}$ for others. To analyze the three-dimensional flow in the tank, massless fluid particles are tracked using the Lagrangian particle tracking system [48].

Naher et al. after four years of his first attempt in 2003 used computational and experimental analysis to measure and predict particulate distribution during $\mathrm{Al}-\mathrm{SiC} \mathrm{MMC}$ fabrication at the same scale as in Figure 2 above. They stated that achieving fully uniform suspensions of particulate distribution during $\mathrm{Al}-\mathrm{SiC}$ MMC fabrication needed only a couple of seconds at the lower and an hour for a higher viscosity system. They try to analyze many factors which influence the incorporation of particulate in metal matrix composites (MMCs) that include particle pushing during solidification, nonwetting, clustering, and settling before quenching [49].

In the study by Ravi et al., impeller blade angle, rotating speed, impeller rotation direction, and baffles were all studied and adjusted as essential mixing characteristics. They demonstrated that a lower impeller blade angle generates large pressure heads, especially beneath the impeller, to overcome large static heads. They also compared experimental results; it was discovered that clockwise stirrer rotation produces more uniform particle distribution than counterclockwise rotation as shown in Figure 5, without 


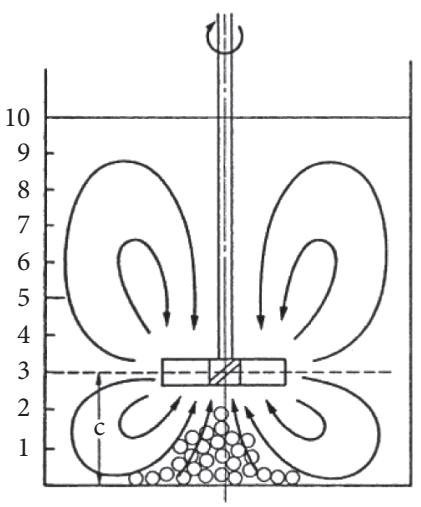

(a)

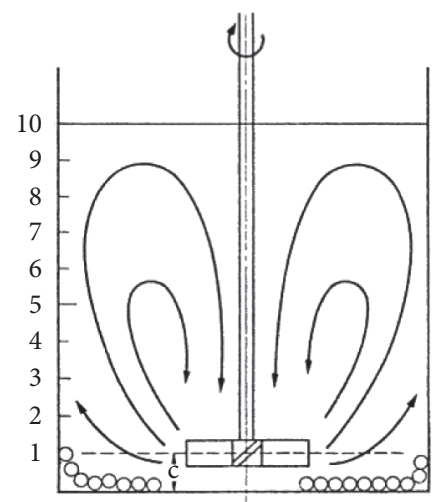

(b)

FIgURE 1: (a, b) Two types of solid particle fluidization [46].

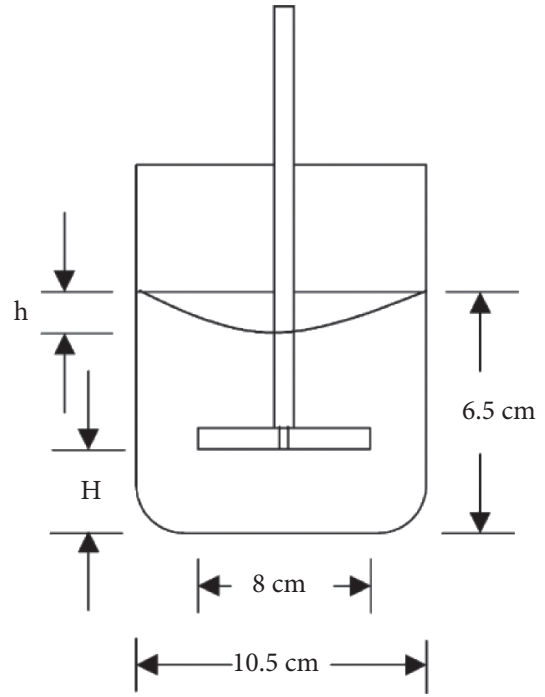

Figure 2: Crucible sketch [8].

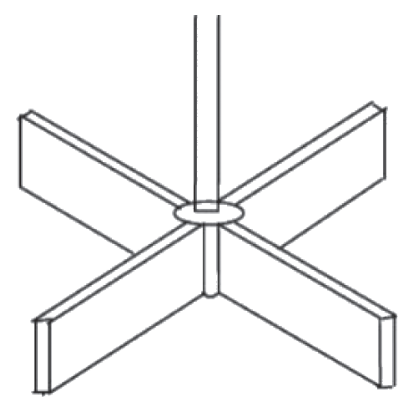

Figure 3: Four-blade stirrer [8].

taking into account the effect of being in the northern or southern hemisphere, which has the opposite effect [50].

$\mathrm{Su}$ et al. simulated the flow behavior of the molten metal in the closed crucible during stir casting by commercial finite element method (FEM) software [12]. The crucible was composed of a cylinder part with a diameter of $210 \mathrm{~mm}$ and a semispherical part, as shown in Figure 6. The height of the

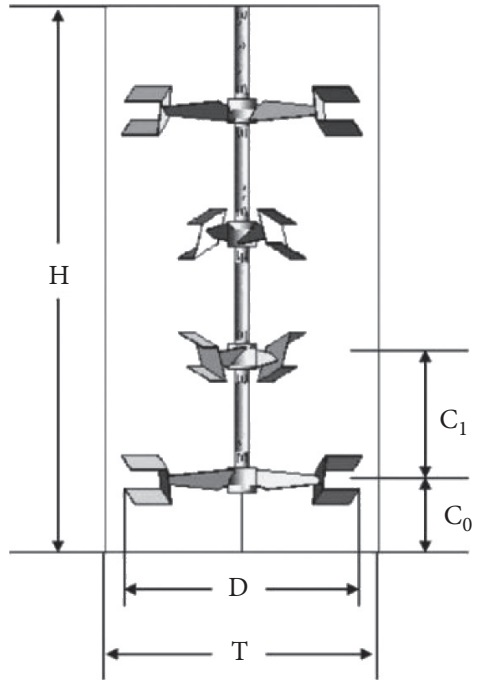

FIgURE 4: Geometry of the vessel equipped with four Intermig impellers [48].

fluid was $380 \mathrm{~mm}$. In this simulation, three types of stirrers were used to investigate the influence of stirrer geometry on the flow pattern.

The flow behavior was influenced by several parameters such as the stirrer design and the stirring speed, and it was difficult to differentiate between their effects on their own. They evaluated the effect of the stirrer design (geometry, the blade angle, and the d/D value) and stirring speed. The impeller blade width is $0.2 \mathrm{D}$ with an angle of 30 degrees as sketched out in Figure 7.

The volume fraction of the stagnant region in the cylinder part decreases noticeably as the geometry ranges from single stage to multistage. The majority of the crucible's regions are nearly stagnant, and a dead zone can be seen at the bottom as shown in Figure 8.

The multistage stirred vessel has two circulation profiles as shown in Figure 9. The second flow pattern is much better for liquid-solid mixing because it can have a higher mixing power, which is particularly important in viscous liquids [12]. 

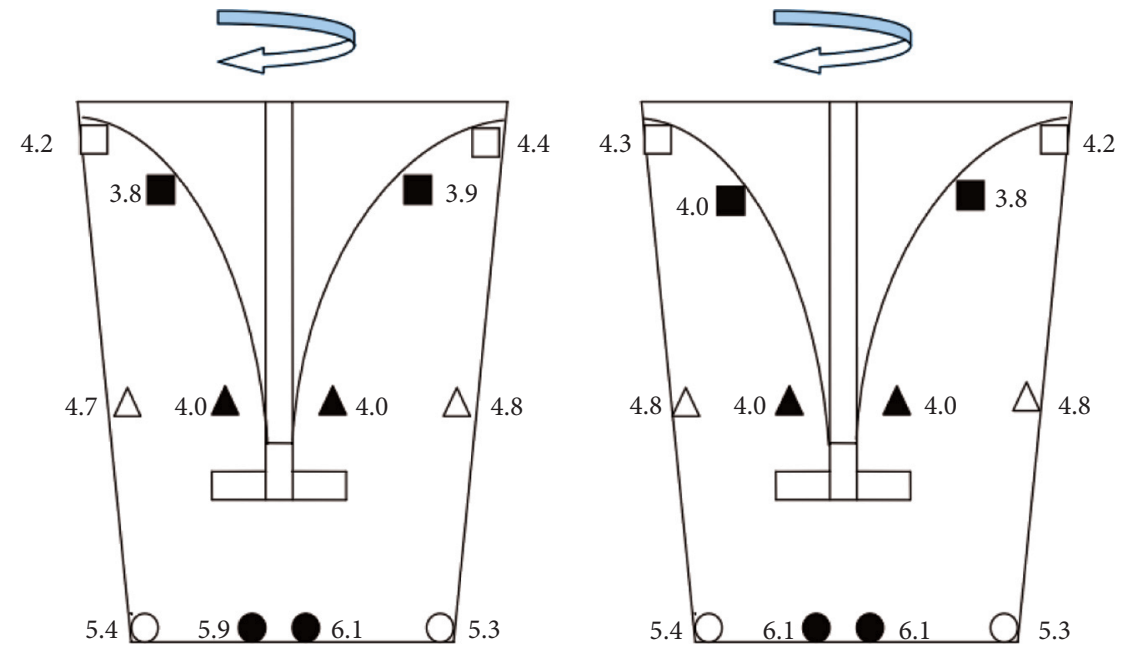

Figure 5: Clockwise rotation of the stirrer [50].

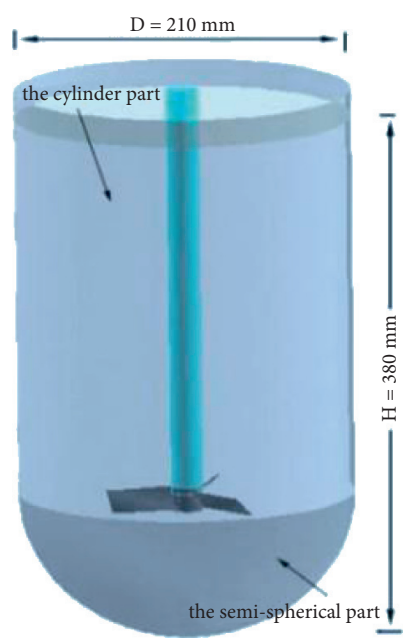

(a)

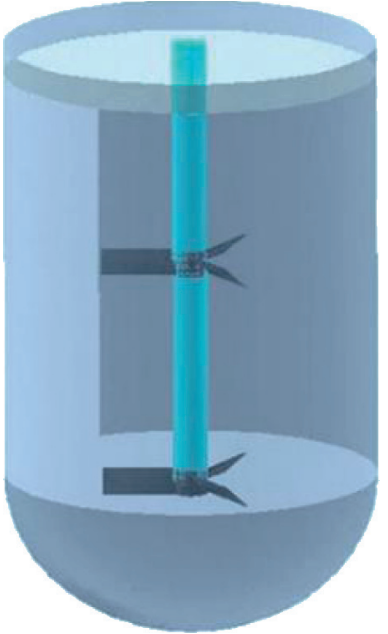

(b)

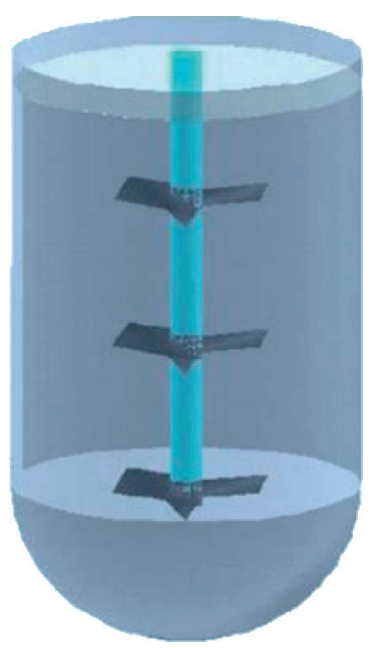

(c)

Figure 6: Geometrical model of the crucible and the stirrer [12]. (a) Single-stage stirrer. (b) Two-stage stirrer. (c) The multi-stage stirrer.
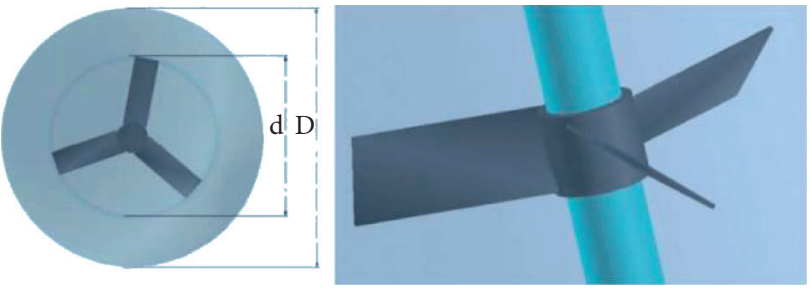

FIGURE 7: Three-blade impeller sketch [12].

Finally, they concluded that the multistage stirrer with a stirring speed of about $1000 \mathrm{rpm}$ and a blade at a 30-degree angle to the stirrer are the best handling conditions for achieving a uniform distribution of particle reinforcement [12].

Sahu and Sahu in their reviewed chapter offered some suggestions without mentioning their specific conditions about the stirring parameters that should be used in the industrial manufacture of AMCs and HAMCs with outstanding mechanical properties. However, authors confirmed that double-stage and multistage stirrer are generally used in chemical industries whereas single-stage impeller stirrer is commonly used for manufacturing AMCs and HAMCs due to flexibility and to avoid unnecessary vortex flow. Figure 10 is adopted from Figure 11 [10].

When the blade angle was greater than 30 degrees, the shearing action was better but the axial flow was less, and when the blade angle was less than 30 degrees, the axial flow was better but the shearing action was less. They concluded that feeding of reinforcement particles is a critical parameter for avoiding particle clustering and they explained that the feed rate of reinforcement particles should be between 0.8 and $1.5 \mathrm{~g} / \mathrm{s}$ to minimize reinforcement particle buildup without mentioning feeder position according to the stirrer position [10].

Shanmughasundaram et al. used design of experiments (DOE), Taguchi, Analysis of Variance (ANOVA), and Multiple Linear Regression Models to optimize parameters 


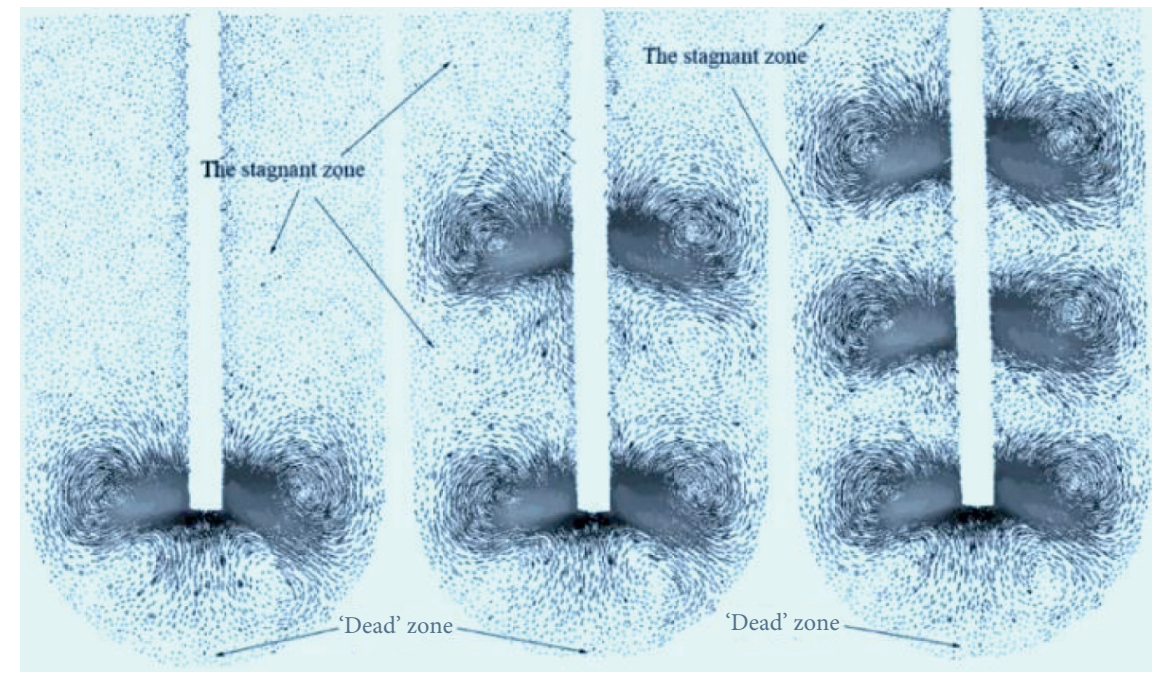

(a)

(b)

(c)

FIGURE 8: Stagnant region and a dead zone in multistage stirrer [12]. (a) Single-stage stirrer. (b) Two-stage stirrer. (c) The multi-stage stirrer.

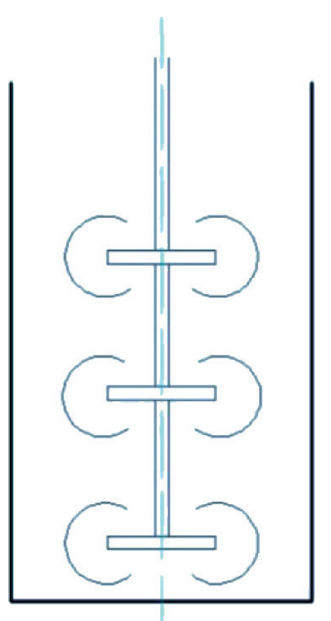

(a)

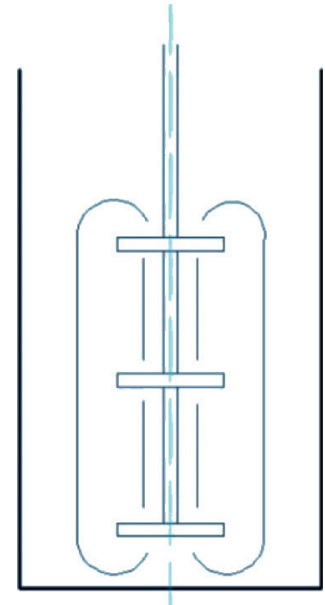

(b)

Figure 9: Two different circulation profiles in the vessel with the multistage stirrer [12].

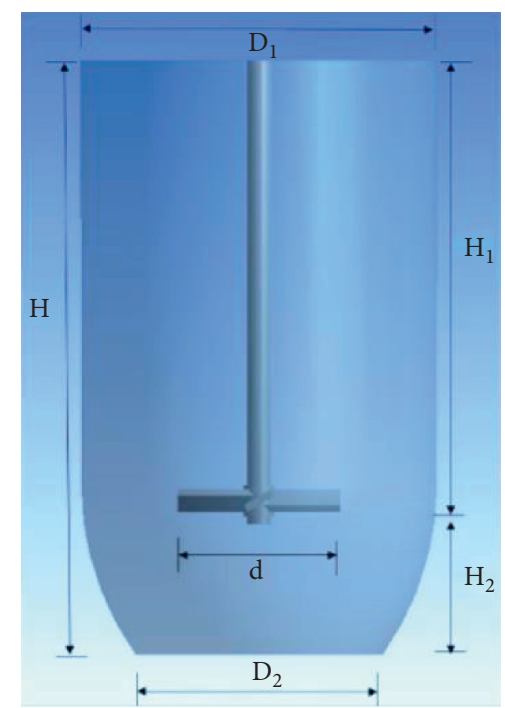

Figure 10: Setup of geometrical of the crucible and stirrer [51]. 


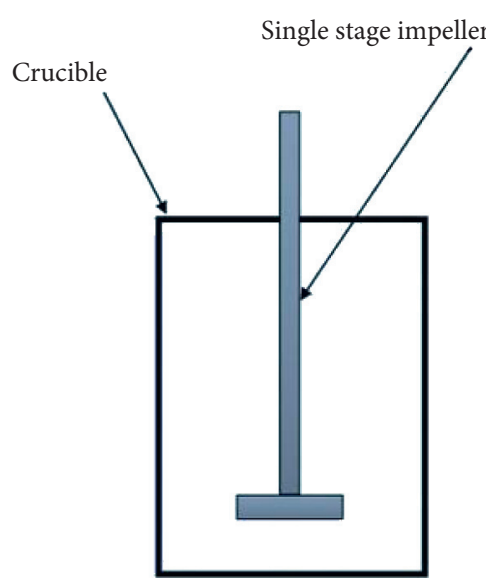

(a)

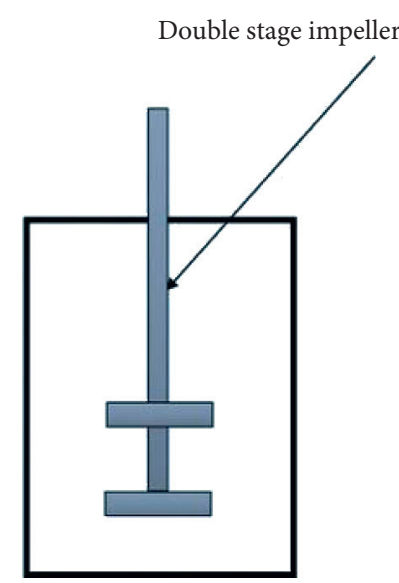

(b)

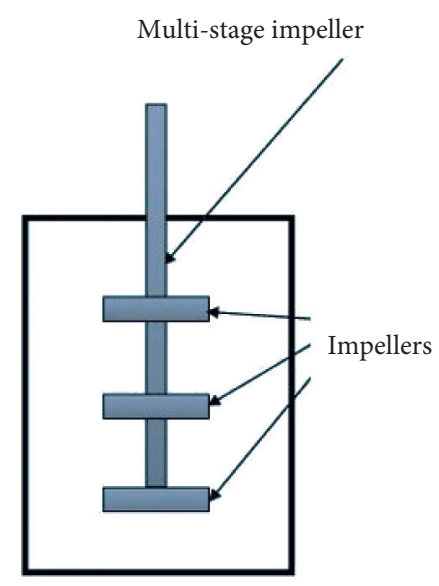

(c)

Figure 11: (a) Single stage. (b) Double stage. (c) Multistage [10].

for the best mechanical properties such as hardness and tensile strength of composites products. They investigated the impact of the impeller outer diameter to crucible inner diameter ratio $(0.7,0.5$, and 0.3$)$ and processing method (liquid state stirring, two-step stirring, and modified twostep stirring) on the distribution of fly ash particles in the $\mathrm{Al}$ matrix, as well as mechanical properties as mentioned in Table 1.

According to the L9 orthogonal array, nine experiments were carried out instead of 27 experiments; the 4 bladed radial impellers with 0.7 of Ci.d/Io.d ratio have statistical significance to ensure uniform distribution of fly ash particles in the $\mathrm{Al}$ matrix. The main plot for $\mathrm{SN}$ ratios-Hardness and Tensile strength shows a positive relationship between the Ci.d/Io.d ratio and the mechanical properties. The optimum combination of each parameter was determined by ANOVA. It can be observed according to the $P$ value; the ratio of impeller outer diameter to crucible inner diameter has only about $9 \%$ impact on the hardness of the composites compared with other factors when it has more than $11 \%$ on tensile strength. Finally, a multiple linear regression equation provided a reasonable explanation for the relationship between the independent and response factors (properties). The final step was the confirmation test which is conducted to validate the predictions [51].

El-Kady et al. studied the optimal process parameters that are relative to stirrer design such as the shape of a stirrer, blade, stirrer position, ratio, and stirrer diameter ratio. As shown in Figure 12 the stirrer relative positions and relative diameters to the crucible size were explained. $h$ is the distance from the bottom of the crucible to the stirrer and $\mathrm{H}$ is the height of the molten slurry from the bottom of the crucible, $d$ is the diameter of the stirrer, and $\mathrm{D}$ is the diameter of the crucible which has $110 \mathrm{~mm}$ diameter and $160 \mathrm{~mm}$ height in an electrical resistance furnace. Figure 13 shows the impeller blades. They included that, with increasing the number of stirrer blades (from two to four), the location ratio $(\mathrm{h} / \mathrm{H})$ (from 0.3 to 0.7$)$, and the diametric ratio (d/D) (from 0.4 to 0.8 ), the porosity of the metal matrix composites decreases [52].
TABLE 1: Factors and levels [52].

\begin{tabular}{lccc}
\hline Levels & $\begin{array}{c}\text { Reinforcements } \\
\text { wt.\% }\end{array}$ & $\begin{array}{c}\text { Ci.d/Io.d } \\
\text { ratio }\end{array}$ & Technique of processing \\
\hline I & 10 & 0.7 & Liquid state \\
II & 15 & 0.5 & Two-step \\
III & 20 & 0.3 & Modified two-step \\
\hline
\end{tabular}

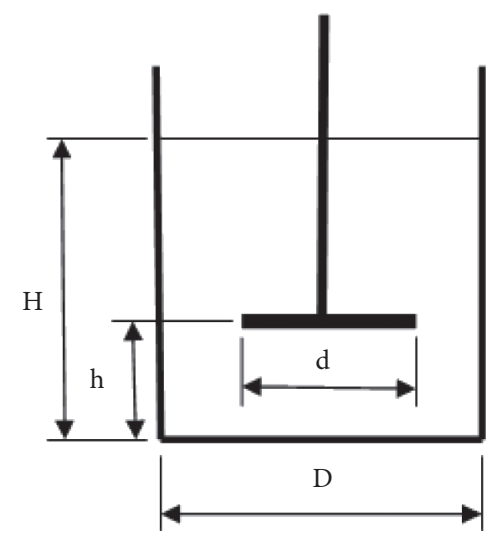

Figure 12: Stirrer to the crucible ratio dimension [53].

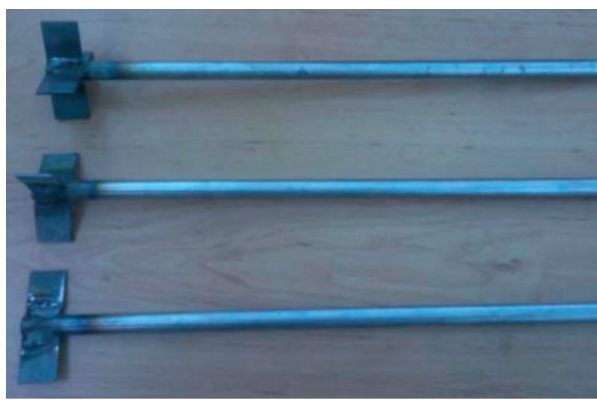

Figure 13: Stirrer with two, three, and four blades [53]. 
Sahu and Sahu used the Grey Taguchi method and ANOVA to optimize the stirring parameters and they concluded that blade angle, impeller size, and stirring speed are significant factors that affect the distribution of reinforcement in hybrid aluminum matrix composites stir casting, according to this study. Impeller size has the greatest influence of more than $66 \%$, followed by blade angle of about (23\%) and stirring speed of about 3\% [53]. The applied crucible has been used before by $\mathrm{Su}$ et al. [12] as shown in Figure 10 with a top diameter of $210 \mathrm{~mm}$ and a bottom diameter of $140 \mathrm{~mm}$. The cylindrical section of the crucible is $275 \mathrm{~mm}$ tall, while the curved bottom portion is $105 \mathrm{~mm}$ tall, with a fluid height of $380 \mathrm{~mm}$. They carried out simulation and experimental methods at optimal combination of stirring parameters for production $\mathrm{Al} 7075 / \mathrm{B} 4 \mathrm{C} / \mathrm{fly}$ ash composite by stir casting. The suggested optimal conditions are blade angle: 30 degrees, impeller size $0.5 \mathrm{D}$, and stirring speed $550 \mathrm{rpm}$.

The number of input factors and their levels are explained in Table 2; the L9 orthogonal array was used. The responses were volume fraction of stagnant zone and dead zone while optimization aimed to reduce the number of undesirable zones. Planimetry analysis was used to calculate the volume fraction of stagnant and dead areas to measure undesired zones.

Vishnu et al. used a four-blade stirrer and a three-blade stirrer in the simulation. Both blade angles were set to 90 degrees in the crucible which has the same dimensions as Figure 7. 100, 150, 200, 250, and $300 \mathrm{rpm}$ blade speeds were simulated. A user-defined function was used to measure the volume-averaged shear rate for each event (UDF). It can be shown that the shear rate produced in the single-phase fluid domain has a direct impact on mixing effectiveness. The findings also show that the shear rate and the uniform dispersion period of particulate matter have a discernible relationship [54].

Yang et al. admitted the stirring time of numerical simulation is very difficult to precisely match the results of the experiment. They used Fluent Version 12.1's Eulerian multiphase model for the simulation of the two-phase flow of aluminum and $\mathrm{SiC}$ in the crucible. In the beginning, they divided the CFD model into three zones: rotation, stationary, and SiC addition zones. The crucible's top wall was set to symmetry, and the bottom wall was set to a stationary wall. The stirring rod wall was set to the rotation wall, which rotated during the simulation. The different positions of the volume fraction of $\mathrm{SiC}$ were controlled at different stirring temperatures, stirring speeds, and stirring times. They concluded that according to the simulation of the shearing force, moments, and stirring power of the stirring rod the $\mathrm{SiC}$ is unwell dispersed at the position closer to the stirring rod without analyzing it [11]. Figure 14 shows the stirring rod and its position when the stirring rod and its blades dimensions are unclear but from the figure it seems it has two stages.

Optimization of stirring parameters was performed to achieve effective flow without stagnant and dead zone [53]. The distribution of particles in the molten matrix is determined by the geometry of the mechanical stirrer, its
TABLE 2: Factors and levels [51].

\begin{tabular}{lccc}
\hline Levels & $\begin{array}{c}\text { Blade angle } \\
(\text { degree })\end{array}$ & $\begin{array}{c}\text { Impeller size } \\
(\mathrm{mm})\end{array}$ & Stirring speed (rpm) \\
\hline I & 30 & $0.5 \mathrm{D}$ & 500 \\
II & 45 & $0.6 \mathrm{D}$ & 550 \\
III & 60 & $0.75 \mathrm{D}$ & 600 \\
\hline
\end{tabular}

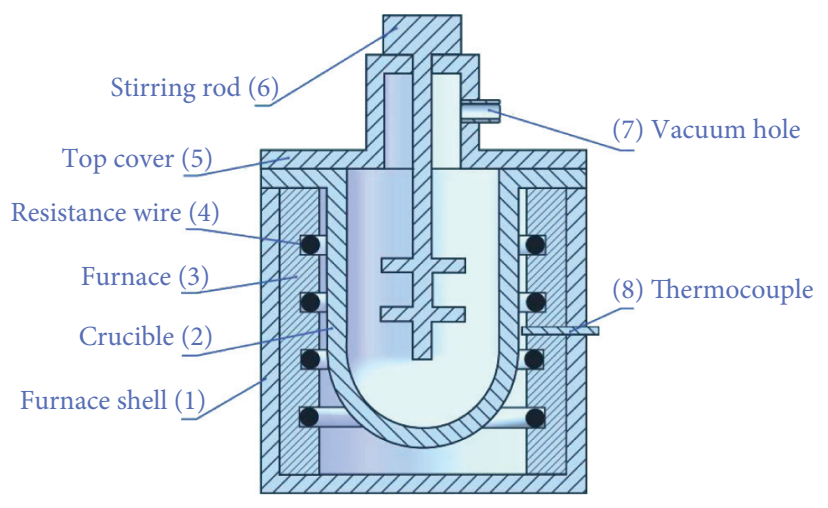

Figure 14: Sketch of the experiment equipment [11].

position in the melt, the melt temperature, and the characteristics of the particles [55-57]. Kayode et al. used the application of large eddy simulation to the prediction of large-scale chaotic structures in stirred tanks. ANSYS CFX v.15.0 was used to simulate the moisture-rich food waste, which was approximated as a Newtonian carrot-orange soup. The homogenizer's velocity and temperature field distributions are investigated at various impeller rotational speeds. It is anticipated that the developed model will help in the selection of a suitable impeller for the efficient mixing of food waste in the homogenizer [58]. The authors studied particle transportation and dispersion in turbulent straight square duct flow using direct numerical simulation and the Lagrangian particle tracking technique [59]. The Eulerian multiphase model and standard $k-\varepsilon$ turbulence model were adopted to simulate the fluid flow, turbulent kinetic energy distribution, mixing performance, and power consumption in a stirred tank. The simulation results were also verified by the water model experiments, and good agreement was achieved [60]. Despite the many differences in details from the studies reviewed about stir casting, the most important steps can be summarized as follows The most important steps of stir casting can be summarized as follows:

(1) Aluminum metals or alloys billets are put in the crucible.

(2) The billets are heated in the furnace until they become liquid.

(3) The stirrer is then dropped into the crucible.

(4) The reheated reinforcements particles are fed to the crucible at a specific rate.

(5) Stirring imparts vortex motion to the aluminum melt. The dispersion of $\mathrm{SiC}$ particles in molten aluminum is caused by stirring. 


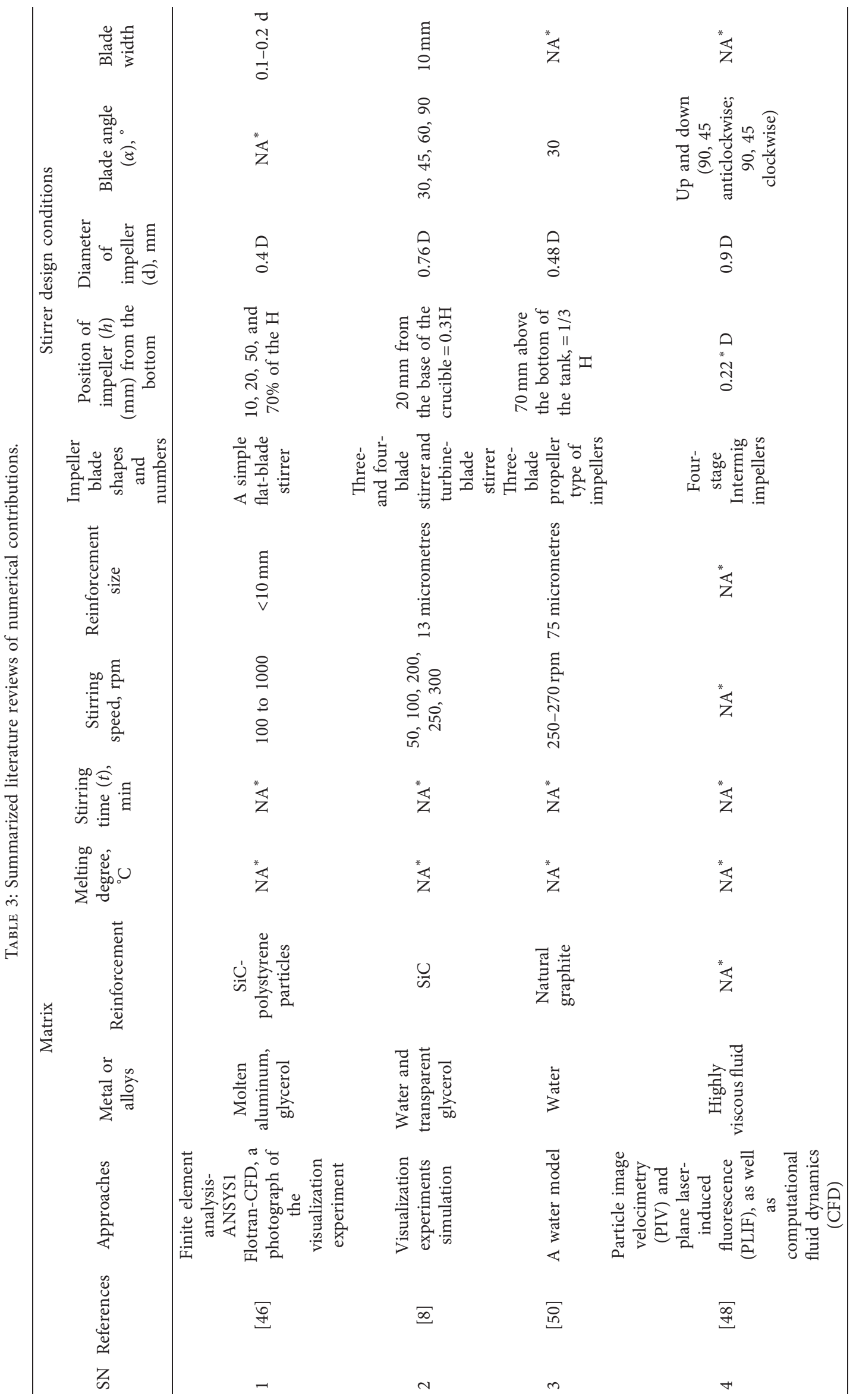




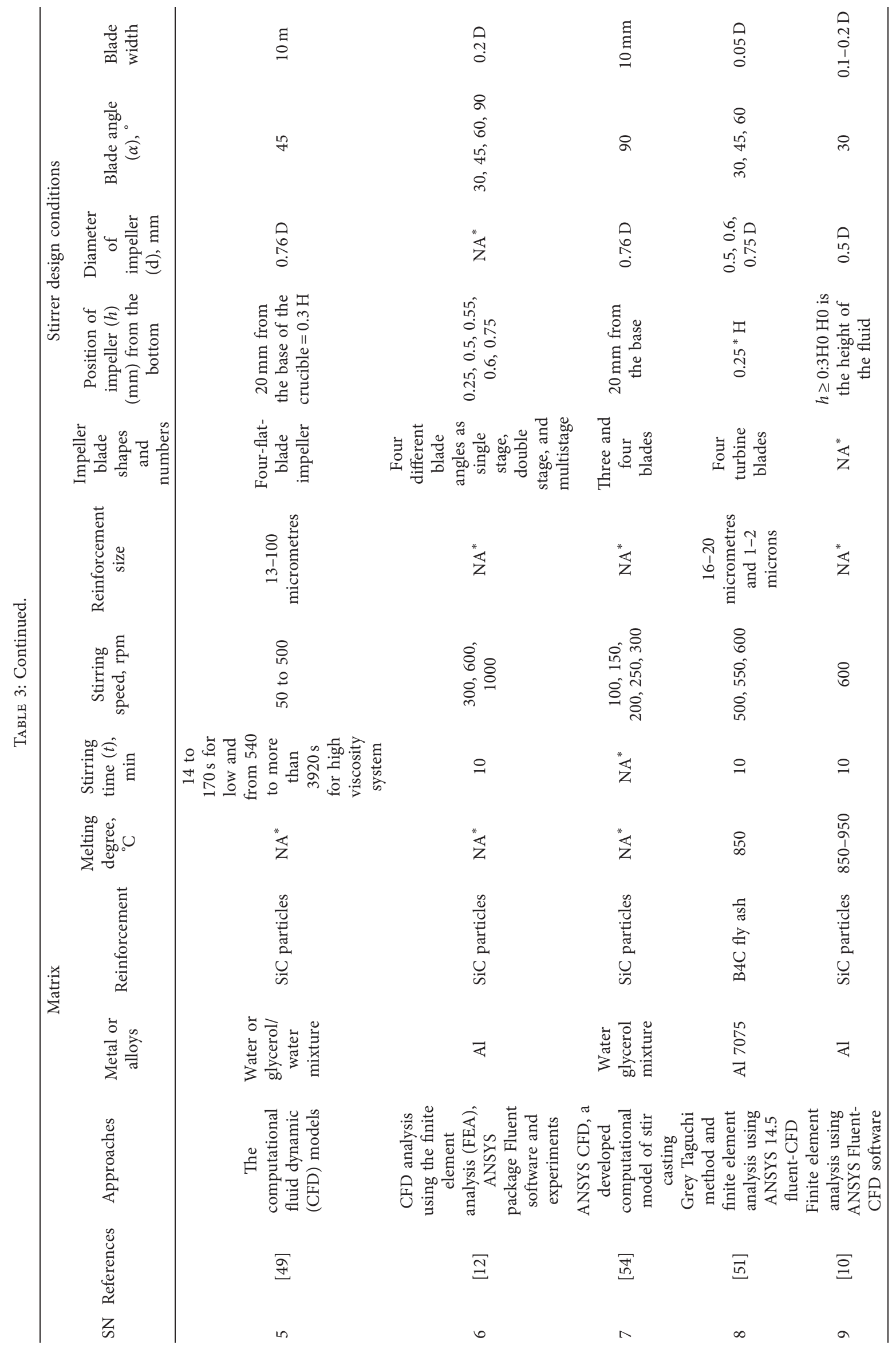




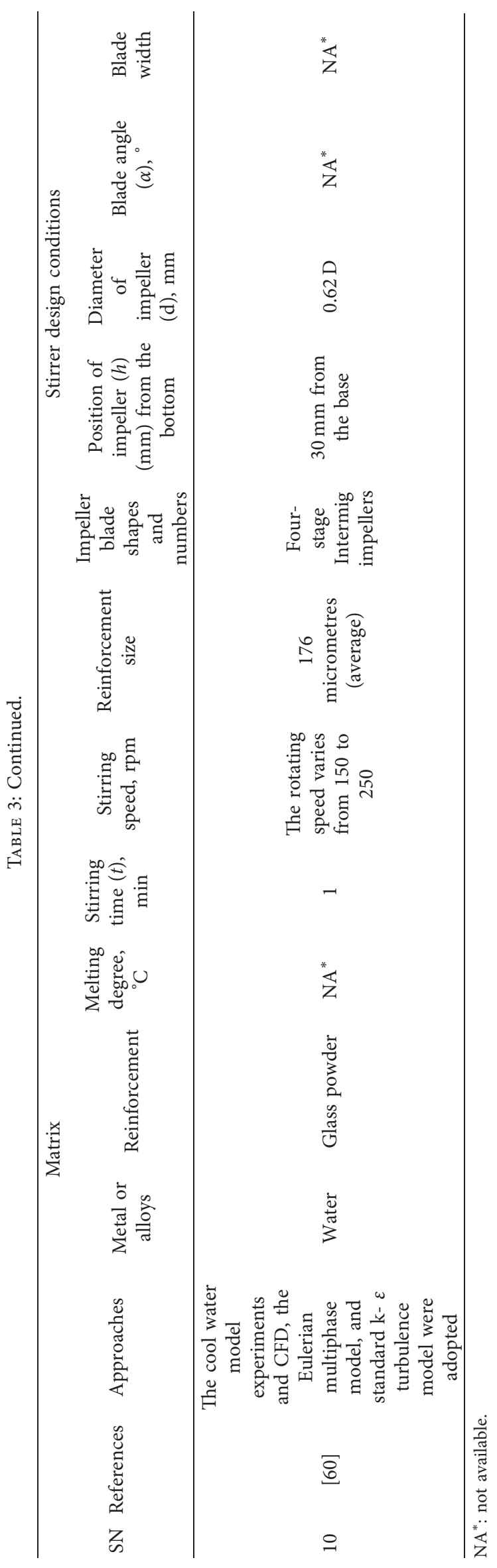




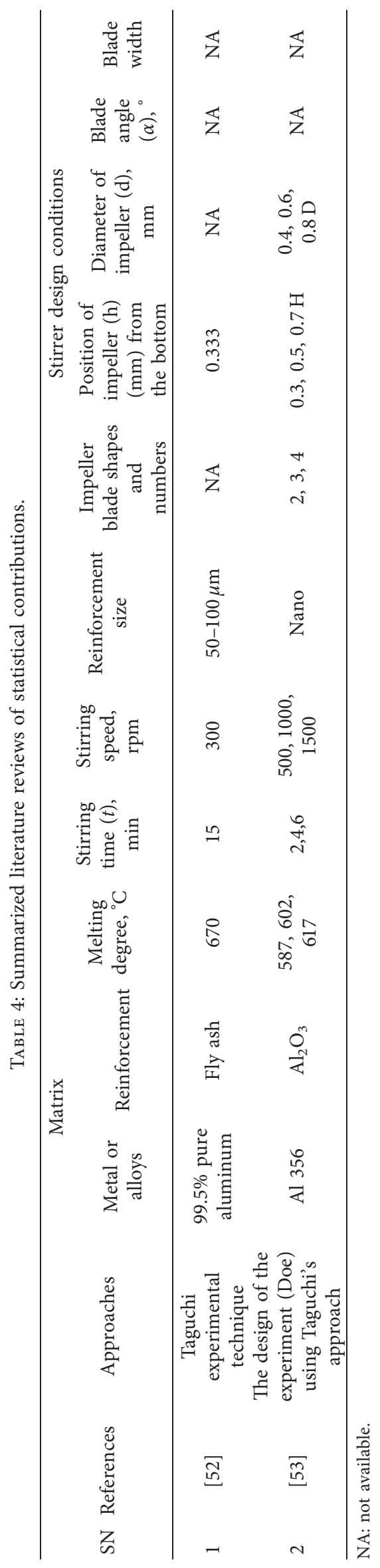


TABLE 5: Summarized literature reviews of statistical and numerical contributions.

\begin{tabular}{|c|c|c|c|c|c|c|c|c|}
\hline \multirow{3}{*}{ SN } & \multirow{3}{*}{ References } & \multirow{3}{*}{ Approaches } & \multicolumn{2}{|c|}{ Matrix } & \multicolumn{4}{|c|}{ Mechanical properties } \\
\hline & & & \multirow[t]{2}{*}{ Metal or alloys } & \multirow[t]{2}{*}{ Reinforcement } & \multicolumn{2}{|c|}{$\begin{array}{c}\text { Tensile } \\
\text { strength, } \\
\text { megapascal }\end{array}$} & \multicolumn{2}{|c|}{ Hardness } \\
\hline & & & & & Before & After & Before & After \\
\hline 1 & {$[52]$} & Taguchi experimental technique & $\begin{array}{l}99.5 \% \text { pure } \\
\text { aluminum }\end{array}$ & Fly ash & 77 & 106 & 19 & $\begin{array}{c}35 \\
\mathrm{BHN}\end{array}$ \\
\hline 2 & {$[53]$} & $\begin{array}{c}\text { The design of the experiment (Doe) using } \\
\text { Taguchi's approach }\end{array}$ & $\mathrm{Al} 356$ & $\mathrm{Al}_{2} \mathrm{O}_{3}$ & 120 & NA & 59 & $\begin{array}{l}42 \text { to } 55 \\
\text { VHN }\end{array}$ \\
\hline 3 & {$[51]$} & $\begin{array}{c}\text { Grey Taguchi method and finite element analysis } \\
\text { using ANSYS } 14.5 \text { fluent-CFD }\end{array}$ & Al 7075 & B4C fly ash & 114 & NA & 127 & $\begin{array}{l}85-95 \\
\text { BHN }\end{array}$ \\
\hline
\end{tabular}

NA: not available.

(6) The melt is transferred to a casting mold when it has been sufficiently mixed.

The influence of the stirrer design on metal matrix composites has been examined in different situations with varied parameters, according to prior studies. The most significant common characteristics and circumstances are shown and summarized in Tables 3-5 in which the mechanical properties have shown direct output results.

\section{Conclusion}

(1) Since the stir casting process involves very high temperatures, experimentation is difficult and dangerous. So proper simulations of the stir casting process considering all relevant factors are necessary to yield good results, and it will help the researchers to identify strategies for experimentation.

(2) After decades of studies conducted to optimize stirring parameters in the stir casting route, the effects of stirrer geometry, the number of blades, blade angle, impeller diameter, stirrer position, and their interactions on the flowing characteristics in the stirred crucible during stir casting remain unknown and not generalizable

(3) The distribution of reinforcement particles was the main output factor, as the central theme of the majority of researchers when they investigated and simulated AMMC. Flow patterns are also studied as pivotal due to their impact on particle distribution.

(4) Stirrer design and stirring speed together affected the flow behavior and it is difficult to distinguish between their impacts alone.

(5) The effect of a stirrer design on mechanical properties is different, and its effect on tensile strength is greater than its effect on hardness.

(6) The number of stirrer stages has significantly affected the homogeneity of particles inside the crucible.

(7) The mixing process is a widespread phenomenon, which plays an essential role among a large number of industrial processes. The effectiveness of mixing depends on the state of mixed phases, temperature, viscosity and density of liquids, mutual solubility of mixed fluids, type of stirrer, and the most critical property, the shape of the impeller.

(8) Among the statistical contributions, the Taguchi method allows for the systematic and efficient design and optimization of some parameters with considerably less work.

(9) The shape of the stirrer, blade geometry, blade angle (degree), impeller size, and the stirrer to the crucible ratio (the diametric ratio $(\mathrm{d} / \mathrm{D})$ ) were investigated by statistical and numerical approaches to optimize the distribution of the particles. They concluded that there is a clear effect of these variables on the flow pattern and then the uniform distribution of the reinforcements in the matrix. They were unable to generalize their findings due to the complexity and a large number of variables.

(10) Finally, the hybrid methodology of theoretical, experimental, analytical, statistical, and numerical simulation should be used to obtain more accurate and validated results.
Abbreviations
MMC: Metal matrix composite
AMC: Aluminum matrix composite
AAMC: Aluminum alloy matrix composite
SiC: $\quad$ Silicon carbide
CFD: Computational fluid dynamics
D: $\quad$ Crucible diameter
d: $\quad$ Impeller blade diameter
$\mathrm{H}$ : Height of crucible
h: Height of impeller from the bottom of the crucible Ho: $\quad$ Height of fluid in the crucible.

\section{Conflicts of Interest}

The authors declare that they have no conflicts of interest.

\section{Acknowledgments}

The authors gratefully acknowledge the support by the College of Engineering at Salahaddin University in ErbilIraq for permitting access to their library. 


\section{References}

[1] A. B. Pandey, K. L. Kendig, and T. J. Watson, Affordable Metal- High Performance Applications, Wiley, Hoboken, NJ, USA, 2001.

[2] M. Ravichandran, M. Meignanamoorthy, G. P. Chellasivam, J. Vairamuthu, A. S. Kumar, and B. Stalin, "Effect of stir casting parameters on properties of cast metal matrix composite," Materials Today: Proceedings, vol. 22, pp. 2606-2613, 2020.

[3] F. A. R. Rozhbiany and S. R. Jalal, "Reinforcement and processing on the machinability and mechanical properties of aluminum matrix composites," Journal of Materials Research and Technology, vol. 8, no. 5, pp. 4766-4777, 2019.

[4] A. Senthil Kumar, A. Deshpande, G. Jain et al., "Processing and characterization mechanical properties of AA2024/ $\mathrm{Al} 2 \mathrm{O} 3 / \mathrm{ZrO} 2 / \mathrm{Gr}$ reinforced hybrid composite using stir casting technique," Materials Today: Proceedings, vol. 37, no. 2, pp. 1562-1566, 2021.

[5] V. Prasad K and K. R. Jayadevan, "On numerical simulation of stirring in stir casting process," Proceedings of the International Conference on Nanotechnology for Better Living, vol. 3, no. 1, p. 296, 2016.

[6] S. S. Shinde, S. G. Kulkarni, and S. S. Kulkarni, "Manufacturing of aluminium matrix composite processing of amc ' S : stir casting," Key Engineering Materials, vol. 2, no. 5, pp. 1-6, 2015.

[7] J. B. Joshi, N. K. Nere, C. V. Rane et al., "CFD simulation of stirred tanks: comparison of turbulence models. part I: radial flow impellers," Canadian Journal of Chemical Engineering, vol. 89, no. 1, pp. 23-82, 2011.

[8] S. Naher, D. Brabazon, and L. Looney, "Simulation of the stir casting process," Journal of Materials Processing Technology, vol. 143, no. 1, pp. 567-571, 2003.

[9] K. Almadhoni and S. Khan, "Review of effective parameters of stir casting process on metallurgical properties of ceramics particulate Al composites," IOSR Journal of Mechanical and Civil Engineering, vol. 12, no. 6, pp. 2278-1684, 2015.

[10] M. K. Sahu and R. K. Sahu, Fabrication of Aluminum Matrix Composites by Stir Casting Technique and Stirring Process Parameters Optimization, Intechopen, London, UK, 2018.

[11] Z. Yang, L. Pan, J. Han et al., "Experimental and simulation research on the influence of stirring parameters on the distribution of particles in cast SiCp/A356 composites," Journal of Engineering, vol. 2017, Article ID 9413060, 11 pages, 2017.

[12] H. Su, W. Gao, H. Zhang, H. Liu, J. Lu, and Z. Lu, "Optimization of stirring parameters through numerical simulation for the preparation of aluminum matrix composite by stir casting process," Journal of Manufacturing Science and Engineering, vol. 132, no. 6, pp. 610071-610077, 2010.

[13] E. Paul, V. Atiemo-obeng, and S. Kresta, Handbook of Industrial Mixing, Wiley, Hoboken, NJ, USA, 2003.

[14] J. George, S. Janardhanan, and T. M. Sijo, “A numerical study on stir casting process in a metal matrix composite using CFD approach," Advanced Materials Research, vol. 1119, pp. 533$541,2015$.

[15] G. O. Verran, R. P. K. Mendes, and L. V. O. D. Valentina, "DOE applied to optimization of aluminum alloy die castings," Journal of Materials Processing Technology, vol. 200, no. 1-3, pp. 120-125, 2008.

[16] T. P. Ryan, Modern Engineering Statistics, Wiley, Hoboken, NJ, USA, 2006.

[17] G. Taguchi, S. Chowdhury, and Y. Wu, Taguchi's Quality Engineering Handbook, Wiley, Hoboken, NJ, USA, 2007.
[18] W. Ding, X. Zhao, T. Chen et al., "Effect of rare earth Y and Al-Ti-B master alloy on the microstructure and mechanical properties of 6063 aluminum alloy," Journal of Alloys and Compounds, vol. 830, Article ID 154685, 2020.

[19] K. Alaneme and M. Bodunrin, "Mechanical behaviour of alumina reinforced AA 6063 metal matrix composites developed by two step-stir casting process," Acta Technica Corviniensis-bulletin Engineering, vol. 6, no. 3, p. 105, 2013.

[20] E. B. Unal and R. Dean, "Taguchi approach to design optimization," in Proceedings of the Annual Conference International Society Parametric Analysis, pp. 1-10, Brussels, Belgium, May 1991.

[21] J. Vairamuthu, B. Stalin, G. D. Sivakumar, B. Mohmed Fazil, R. Balaji, and V. Ananda Natarajan, "The effect of process parameters for synthesized copper metal matrix using stir casting process," Materials Today: Proceedings, vol. 45, pp. 1970-1974, 2021.

[22] M. O. Shabani, M. R. Rahimipour, A. A. Tofigh, and P. Davami, "Refined microstructure of compo cast nanocomposites: the performance of combined neuro-computing, fuzzy logic and particle swarm techniques," Neural Computing \& Applications, vol. 26, no. 4, pp. 899-909, 2015.

[23] A. A. Tofigh and M. O. Shabani, "Efficient optimum solution for high strength Al alloys matrix composites," Ceramics International, vol. 39, no. 7, pp. 7483-7490, 2013.

[24] P. Vijian and V. P. Arunachalam, "Modelling and multi objective optimization of LM24 aluminium alloy squeeze cast process parameters using genetic algorithm," Journal of Materials Processing Technology, vol. 186, no. 1-3, pp. 82-86, 2007.

[25] P. Senthil and K. S. Amirthagadeswaran, "Optimization of squeeze casting parameters for non symmetrical AC2A aluminium alloy castings through Taguchi method," Journal of Mechanical Science and Technology, vol. 26, no. 4, pp. 11411147, 2012.

[26] H. Goyal, N. Mandal, H. Roy, S. K. Mitra, and B. Mondal, "Multi response optimization for processing Al-SiCp composites: an approach towards enhancement of mechanical properties," Transactions of the Indian Institute of Metals, vol. 68 , no. 3, pp. 453-463, 2015.

[27] C. Dhavamani and T. Alwarsamy, "Optimization of machining parameters for aluminum and silicon carbide composite using genetic algorithm," Procedia Engineering, vol. 38, pp. 1994-2004, 2012.

[28] R. Marwaha, R. Gupta, V. Jain, and S. Krishan, "Experimental investigation \& wear parameter on $\mathrm{Al} / \mathrm{SiC} / \mathrm{Gr}-$ metal matrix," Global Journal of Research in Engineering, vol. 13, no. 9, 2013.

[29] N. S. Nikhil, R. V. R. Akhil, K. Thimothy, B. C. Thomas, C. J. Clemin, and P. K. Jerin, "Machining of an aluminum metal matrix composite using tungsten carbide inserts," The International Journal of Engineering And Science, vol. 4, pp. 6-11, 2015, https://fdocuments.in/document/machiningof-an-aluminum-metal-matrix-composite-using-tungstencarbide-inserts.html.

[30] A. C. Reddy., "Influence of volume fraction, size, cracking, clustering of particulates and porosity on the strength and stiffness of 6063/sicp metal matrix composites," International Journal of Renewable Energy Technology, vol. 4, no. 1, pp. 434-442, 2015.

[31] T. Thirumalai, L. Boopathi, and T. Shreedhar, "Manufacturing of aluminium reinforced with quartz in composites," in Proceedings of the International Conference on Emerging trends in Engineering, Science and Sustainable Technology (ICETSST-2017), pp. 30-37, Coimbatore, India, Februray 2017. 
[32] R. Sharma, S. J. P, K. Kakkar, K. Kamboj, and P. Sharma, “A review of the aluminium metal matrix composite and its properties," International Research Journal of Engineering and Technology, vol. 4, no. 2, pp. 832-842, 2017, https://irjet.net/ archives/V4/i2/IRJET-V4I2162.pdf.

[33] M. O. Durowoju, J. O. Agunsoye, L. O. Mudashiru, A. A. Yekinni, S. K. Bello, and T. O. Rabiu, "Optimization of stir casting process parameters to improve the hardness property of Al/RHA matrix composites," European Journal of Engineering Research and Science, vol. 2, no. 11, p. 5, 2017.

[34] S. K. Prajapati and N. Kumar, "Stir design to improve uniform distribution of composite materials in stir casting process," International Journal of Advanced Technology and Engineering Exploration, vol. 5, no. 47, pp. 419-425, 2018.

[35] M. Ravikumar, H. N. Reddappa, and R. Suresh, “Aluminium composites fabrication technique and effect of improvement in their mechanical properties-a review," Materials Today: Proceedings, vol. 5, no. 11, pp. 23796-23805, 2018.

[36] A. P. Kumar, B. J. Naik, C. V. Rao, and S. R. Rao, "Optimization of casting parameters for casting of AL/RHA/RM hybrid composites using Taguchi method," International Journal of Engineering Trends and Technology, vol. 235, 2019.

[37] H. Hanizam, M. S. Salleh, M. Z. Omar, and A. B. Sulong, "Optimisation of mechanical stir casting parameters for fabrication of carbon nanotubes-aluminium alloy composite through Taguchi method," Journal of Materials Research and Technology, vol. 8, no. 2, pp. 2223-2231, 2019.

[38] A. Manivannan and R. Sasikumar, "Exemplary encapsulate feeding in stir casting for quality composites," Materials and Manufacturing Processes, vol. 34, no. 6, pp. 689-694, 2019.

[39] A. Ramanathan, P. K. Krishnan, and R. Muraliraja, "A review on the production of metal matrix composites through stir casting-furnace design, properties, challenges, and research opportunities," Journal of Manufacturing Processes, vol. 42, pp. 213-245, 2019.

[40] P. P. Kulkarni, B. Siddeswarappa, and K. S. H. Kumar, "A survey on effect of agro waste ash as reinforcement on aluminium base metal matrix composites," Open Journal of Composite Materials, vol. 9, no. 3, pp. 312-326, 2019.

[41] R. T. Bui, R. Ouellet, and D. Kocaefe, "A two-phase flow model of the stirring of Al-SiC composite melt," Metallurgical and Materials Transactions B, vol. 25, no. 4, pp. 607-618, 1994.

[42] J. Hashim, L. Looney, and M. S. J. Hashmi, "Particle distribution in cast metal matrix composites -part I," Journal of Materials Processing Technology, vol. 123, no. 1, pp. 251-257, 2002.

[43] R. A. Gore and C. T. Crowe, "Effect of particle size on modulating turbulent intensity," International Journal of Multiphase Flow, vol. 15, no. 2, pp. 279-285, 1989.

[44] D. Kocaefe and R. T. Bui, "A one-phase model of the mixing of Al-SiC composite melt," Metallurgical and Materials Transactions B, vol. 27, no. 6, pp. 1015-1023, 1996.

[45] P. K. Rohatgi, J. Sobczak, R. Asthana, and J. K. Kim, "Inhomogeneities in silicon carbide distribution in stirred liquids-a water model study for synthesis of composites," Materials Science and Engineering A, vol. 252, no. 1, pp. 98108, 1998.

[46] J. Hashim, L. Looney, and M. S. J. Hashmi, "Particle distribution in cast metal matrix composites-part II," Journal of Materials Processing Technology, vol. 123, no. 2, pp. 258-263, 2002.

[47] S. Nagata, Mixing-Principles-And-Applications, John Wiley \& Sons, Hoboken, NJ, USA, 1975.
[48] J. Aubin and C. Xuereb, "Design of multiple impeller stirred tanks for the mixing of highly viscous fluids using CFD," Chemical Engineering Science, vol. 61, no. 9, pp. 2913-2920, 2006.

[49] S. Naher, D. Brabazon, and L. Looney, "Computational and experimental analysis of particulate distribution during AlSiC MMC fabrication," Composites Part A: Applied Science and Manufacturing, vol. 38, no. 3, pp. 719-729, 2007.

[50] K. R. Ravi, V. M. Sreekumar, R. M. Pillai et al., "Optimization of mixing parameters through a water model for metal matrix composites synthesis," Materials \& Design, vol. 28, no. 3, pp. 871-881, 2007.

[51] M. K. Sahu and R. K. Sahu, "Optimization of stirring parameters using CFD simulations for HAMCs synthesis by stir casting process," Transactions of the Indian Institute of Metals, vol. 70, no. 10, pp. 2563-2570, 2017.

[52] P. Shanmughasundaram, R. Subramanian, and G. Prabhu, "Synthesis of Al-fly ash composites by modified two step stir casting method," Advanced Materials Research, vol. 488-489, pp. 775-781, 2012.

[53] E. Y. El -Kady, T. S. Mahmoud, A.-A. Mohamed, and T. Khalil, "On the fabrication of A356/Al2O3 metal matrix composites using rheocasting and squeeze casting techniques," Journal Material Science Engineering, vol. 2, 2014.

[54] K. Vishnu Prasad and K. R. Jayadevan, "Simulation of stirring in stir casting," Procedia Technology, vol. 24, pp. 356-363, 2016.

[55] S. Suresh, A. Mortensen, and A. Needleman, Fundamentals of Metal-Matrix Composites, Butterworth-Heinemann, Oxford, UK, 2013.

[56] N. Harnby, M. F. Edwards, and A. W. Nienow, Mixing in the Process Industries, Elsevier, Amsterdam, Netherlands, 2nd edition, 1985.

[57] H. Kala, K. K. S. Mer, and S. Kumar, "A review on mechanical and tribological behaviors of stir cast aluminum matrix composites," Procedia Materials Science, vol. 6, pp. 1951-1960, 2014.

[58] I. Kayode, E. Ogedengbe, and M. Rosen, "Design of stirrer impeller with variable operational speed for a food waste homogenizer," Sustainability, vol. 8, no. 5, p. 489, 2016.

[59] Y. Wang, Y. Zhao, and J. Yao, "Particle dispersion in turbulent, square open duct flows of high reynolds number," Powder Technology, vol. 354, pp. 92-107, 2019.

[60] X. Li, H. Zhao, Z. Zhang, Y. Liu, and T. A. Zhang, "Numerical optimization for blades of intermig impeller in solid-liquid stirred tank," Chinese Journal of Chemical Engineering, vol. 29, pp. 57-66, 2021. 